\title{
Interleukin-17A and interleukin-23 in morphea
}

\author{
Aleksandra Dańczak-Pazdrowskaㄹ, Michał Kowalczyk ${ }^{1}$, Beata Szramka-Pawlak, \\ Justyna Gornowicz-Porowska, Aleksandra Szewczyk¹, Wojciech Silny ${ }^{1}$, Anna Olewicz-Gawlik², \\ Marta Molińska-Glura³ ${ }^{3}$ Ryszard Żaba', Paweł Hrycaj ${ }^{2}$
}

\author{
1Department of Dermatology, Poznan University of Medical Sciences, Poznan, Poland \\ 2Department of Rheumatology and Clinical Immunology, Poznan University \\ of Medical Sciences, Poznan, Poland \\ ${ }^{3}$ Chair and Department of Computer Science and Statistics, Poznan University \\ of Medical Sciences, Poznan, Poland
}

Submitted: 27 January 2012

Accepted: 8 April 2012

Arch Med Sci 2012; 8, 6: 1089-1095

DOI: 10.5114 /aoms.2012.32421

Copyright @ 2012 Termedia \& Banach

\begin{abstract}
Introduction: Morphea is a disease included in the group of scleroderma type autoimmune diseases. Interleukin (IL)-17A may play a role at every stage of its pathogenesis. The study aimed at evaluation of IL-17A and IL-23 (as the main cytokine which is supposed to stimulate and maintain synthesis of IL-17) in pathogenesis of morphea.

Material and methods: The studies were performed on 41 blood samples from patients with morphea. Skin was sampled from 29 patients. The evaluation included: (1) expression of IL-17A and IL-23 genes in peripheral blood mononuclear cells (PBMC) using real-time polymerase chain reaction (PCR), (2) plasma concentrations of IL-17A and IL-23 using ELISA, (3) expression of IL-17A and IL-23 genes in skin using real-time PCR.

Results: The results of gene expression are expressed as median number of copies per million copies of GAPDH. Higher expression of IL-17A has been demonstrated in PBMC of morphea vs. control group (2630 and 1906 respectively; $p=0.004$ ), accompanied by absence of significant differences in its plasma concentration (10 pg/ml in both groups) and by lowered expression in affected skin (9119 and 19113 respectively; $p=0.036$ ). The results failed to demonstrate elevated IL-23 plasma concentration in morphea vs. control group $(5 \mathrm{pg} / \mathrm{ml}$ and $6 \mathrm{pg} / \mathrm{ml}$ respectively; $p=0.335$ ) or its increased expression in the skin (292 vs. 427; $p=0.383$ ), although we noted its increased expression in PBMC (4419 vs. 808; $p<0.001)$.

Conclusions: Based on the observed correlations we suggest that: (1) IL-17A does not represent a factor which promotes tissue injury in morphea, (2) IL-23 may playa role in pathogenesis of morphea.
\end{abstract}

Key words: morphea, scleroderma, interleukin 17, interleukin 23, autoimmune diseases.

\section{Introduction}

Morphea, also termed localized or circumscribed scleroderma, is a condition classified as an autoimmune connective tissue disease. In its classic varieties, including morphea en plaques (MEP), generalized morphea (GM), linear morphea (LM) and deep morphea (DM), it leads to dermal thickening, defined as scleroderma. Thus, it resembles systemic sclerosis (SSc) and a number of scleroderma-like diseases [1-5]. Pathogenesis of the disease remains unknown. It is postulated that, as in SSc, the primary phenomenon

\author{
Corresponding author: \\ Aleksandra Dańczak- \\ Pazdrowska MD, PhD \\ Department of Dermatology \\ Poznan University \\ of Medical Sciences \\ 49 Przybyszewskiego St \\ 60-355 Poznan, Poland \\ Phone: 602158360 \\ E-mail: aleksandra.pazdrowska@ \\ onet.eu
}


A. Dańczak-Pazdrowska, M. Kowalczyk, B. Szramka-Pawlak, J. Gornowicz-Porowska, A. Szewczyk, W. Silny, A. Olewicz-Gawlik,

M. Molińska-Glura, R. Żaba, P. Hrycaj

involves injury of endothelial cells, which is followed by a cascade of immune events, including autoaggression and, finally, leads to a disturbed turnover of extracellular matrix [2, 3, 6-9]. Interestingly, interleukin (IL)-17, the significance of which has been postulated recently in several autoimmune diseases, including SSc [10-14], may potentially play a role in all of the above listed processes which are supposed to participate in pathogenesis of morphea. The interleukin induces synthesis of many cytokines (including IL-1 and IL-8) and of several proteins engaged in tissue remodelling. It promotes proliferation and differentiation of naïve $B$ lymphocytes to plasma cells [13-16]. Its involvement is also postulated in processes of angiogenesis, which it can stimulate both directly and indirectly, inducing synthesis of proteins such as IL-8, vascular endothelial growth factor (VEGF), hepatocyte growth factor (HGF), and fibroblast growth factor (FGF). Interleukin-17 is also supposed to induce apoptosis of endothelial cells [1719]. As shown by earlier observations, the principal cytokine in humans supposed to induce and support synthesis of IL-17 is IL-23 [20, 21].

This study was aimed at evaluation of IL-17A and IL-23 in pathogenesis of morphea.

\section{Material and methods}

\section{Material}

The study was performed on 41 morphea patients (mean age: 43.7 years; standard deviation $(\mathrm{SD})=17.5$; 22 women, 19 men), among whom MEP was diagnosed in 20 patients, GM in 14 patients and LM in 7 patients. In all the patients qualified for the study the diagnosis was confirmed by histopathology. The patients were subdivided into subgroups according to the clinical criteria provided by Peterson et al. [1] and Kreuter et al. [3]. Blood was sampled from every patient of the study group. Skin samples from the lesions were obtained from 29 patients. The control groups included, respectively, 47 healthy volunteers (mean age: 33 years, $\mathrm{SD}=8.9$ years, 35 women, 12 men) from whom blood was obtained, and 13 patients with breast carcinoma, manifesting no skin involvement (mean age: 52 years, SD = 17.6 years), from whom samples of healthy skin were obtained directly following mastectomy. The study protocol was approved by the local bioethical committee and all patients and volunteers gave written consent.

Around $5 \mathrm{ml}$ of blood was collected in EDTA-containing vacutainers (Monovette, Sarstedt). Peripheral blood mononuclear cells (PBMC) and plasma were obtained by centrifugation in Ficoll density gradient (Ficoll-Histopaque $1.070 \mathrm{~g} / \mathrm{cm}^{3}$, Sigma Diagnostics, Inc. St. Louis, USA). Until tested, the plasma was stored at the temperature of $-80^{\circ} \mathrm{C}$.
Skin samples directly after isolation were frozen in liquid nitrogen and, until tested, stored at the temperature of $-80^{\circ} \mathrm{C}$.

\section{Methods \\ Evaluation of skin lesion range, intensity and activity}

The patients were subjected to evaluation of skin lesion range, intensity and activity in morphea using the index suggested by Arkachaisri and Pino (Localized Scleroderma Severity Index, LoSSI) [22]. The maximum potential score was 168 [22].

\section{Enzyme-linked immunosorbent assay (ELISA)}

Studies on plasma concentration of IL-17A and IL-23 were conducted using commercially available ELISA kits of R\&D Systems (Minneapolis, USA). The estimations were performed as recommended by the manufacturer.

Expression of IL-17A and IL-23 genes in PBMC was estimated by real-time polymerase chain reaction (PCR).

Total RNA, isolated from PBMC, was obtained with a modified Chomczyński and Sacchi protocol [23]. In order to avoid contamination with genomic DNA, a kit with recombinant DNase I (Ambion, USA) was used. In every case $1 \mu \mathrm{g}$ RNA was taken for the reaction. Reverse transcription (RT) was performed with a commercially available kit (Roche Applied Science). cDNA samples obtained by RT were subjected to quantitative analysis of expression using real-time PCR. The analyses took advantage of the Light Cycler 2 system (Roche Diagnostics $\mathrm{GmbH}$, Germany) and commercial kits for real-time PCR, containing SYBR Green (SG) dye (Roche Applied Science).

The analysis included selected gene fragments, of 78-201 base pairs in length (bp). In every case the amplicons encompassed at least one intron, which - in combination with an appropriately short elongation time - minimized the potential for amplification of undesirable sequences of genomic origin. Efficacy of DNase I action, and hence efficacy of eliminating genomic DNase I contaminations, was confirmed by real-time PCR on material not subjected to RT (negative no-RT control). Primers used in the experiments were designed taking advantage of base sequences available in the Ensembl database or obtained from the Internet database: http://www.rtprimerdb.org/ [24, 25] (Table I).

Real-time PCR was optimized, adjusting amplification parameters and the reaction composition to obtain the best possible results. Product size was evaluated by electrophoresis in agarose gel with the SYBR Safe stain (Invitrogen). The reaction was regarded as optimized when a single band of cor- 
Table I. Primers used in the study

\begin{tabular}{|c|c|c|c|}
\hline Name & Sequence $5^{\prime}-3^{\prime}$ & Amplicon length [bp] & Source or base sequence \\
\hline GAPDH-F & CTGCACCACCAACTGCTTAG & \multirow[t]{2}{*}{105} & \multirow{2}{*}{$\begin{array}{l}\text { Ensembl: ENST00000229239 } \\
\text { Glyceraldehyde-3-phosphate dehydrogenase }\end{array}$} \\
\hline GAPDH-R & TTCTGGGTGGCAGTGATG & & \\
\hline IL17A-F & CTCATTGGTGTCACTGCTACTG & \multirow[t]{2}{*}{78} & \multirow[t]{2}{*}{ http://www.rtprimerdb.org/assay id=7754 } \\
\hline IL17A-R & CCTGGATTTCGTGGGATTGTG & & \\
\hline IL23-F & ACACATGGATCTAAGAGAAGAGG & \multirow[t]{2}{*}{201} & \multirow[t]{2}{*}{ http://www.rtprimerdb.org/assay id=7758 } \\
\hline IL23-R & CTATCAGGGAGCAGAGAAGG & & \\
\hline
\end{tabular}

rect size was detected in agarose gel and when the analysis of amplicon melting temperature following real-time PCR reaction pointed to a single and homogeneous product of amplification. Quantitative determination of studied transcripts was conducted based on standard curves prepared for samples of synthetic DNA of known concentrations. The obtained results were expressed as numbers of copies per million copies of transcripts related to the reference gene of glyceraldehyde-3-phosphate dehydrogenase (GAPDH). The choice of using this particular reference gene in the case of the described studies is justified in the literature [26].

Studies on expression of IL-17A and IL-23 genes in skin using real-time PCR

Total RNA was isolated from skin biopsies using rotor-stator homogenization of the deep frozen samples in the TriPure reagent (Roche Applied Science). Due to the presence of large amounts of contaminants, double phenol-chloroform extraction was performed, with washes in isopropanol and $75 \%$ ethanol. In addition, all the preparations were subjected to digestion with recombinant DNase I. The subsequent stages of evaluating expression were identical to those used for material obtained from PBMC.

\section{Evaluation of antinuclear antibodies (ANA)}

Examination of ANA titre using indirect immunofluorescence against a mosaic of substrates (a neoplastic cell line of laryngeal cancer, HEp-2/monkey liver) was conducted using a commercially available kit (Euroimmun, Lübeck, Germany).

\section{Statistical analysis}

The statistical analysis was performed on Statistica 9.1 statistical software (StatSoft). In order to describe variability within the studied morphea group, its subgroups and control groups, appropriate descriptive statistics were prepared, including mean and SD for age and duration of the disease and, in view of the unfulfilled assumptions as to the normal distribution of the data, the median, minimum and maximum values for the remaining analysed variables. Significance of differences between the study group and control groups was evaluated using the Mann-Whitney $U$ test. Significance of differences in distribution of variables in individual subtypes of the disease was evaluated using the ANOVA Kruskal-Wallis test. For description of relationships between LOSSI, duration of the disease and the analysed variables, both in subgroups and in the entire group, Spearman's rank correlation method was used. The results were regarded significant at $p<0.05$. Graphically, the results were presented in box graphs.

\section{Results}

Intensity and duration of disease are presented in Table II. Plasma concentration of IL-17A and its expression in PBMC and skin in the study group and the control group are presented in Table III. Plasma

Table II. Values of descriptive statistics for LoSSI and duration of the disease in study group

\begin{tabular}{|llccccc|}
\hline Variables & & Morphea & & Subtypes of morphea \\
\cline { 3 - 7 } & & & MEP & GM & LM \\
\hline Number of patients & $n$ & 41 & 20 & 14 & 7 \\
\hline Duration of the disease & Mean [years] & 5.4 & 8.0 & 3.4 & 3.9 & 14.3 \\
\cline { 2 - 7 } & SD & 7 & 4.5 & 14 & 17.3 \\
\hline LoSSI & Median & $2-59$ & $2-10$ & $10-32$ & $6-59$ \\
\cline { 2 - 7 }
\end{tabular}

MEP - morphea en plaques, GM - generalized morphea, LM - linear morphea, SD - standard deviation, LoSSI - Localized Scleroderma Severity Index according to Arkachaisri et al. [15], min. - minimum value, max. - maximum value 
A. Dańczak-Pazdrowska, M. Kowalczyk, B. Szramka-Pawlak, J. Gornowicz-Porowska, A. Szewczyk, W. Silny, A. Olewicz-Gawlik, M. Molińska-Glura, R. Żaba, P. Hrycaj

concentration of IL-23 and its expression in PBMC and in skin of the study and the control groups are shown in Table IV. Results of the indirect immunofluorescent examination evaluating presence and titre of ANA are presented in Table V.

Significantly higher expression levels of both IL-17A and IL-23 were detected in PBMC of morphea patients, as compared to the control group $(p=0.004$ and $p<0.001$, respectively). Similar results were obtained in the MEP subgroup ( $p=0.004$ and $p<0.001$, respectively). On the other hand, in the subgroups of $L M$ and GM, expression of IL-17A in PBMC manifested no significant difference as compared to the control group but expression of

Table III. Expression of IL-17A gene in PBMC, its plasma concentration and cutaneous expression in the study and control groups

\begin{tabular}{|c|c|c|c|c|c|c|}
\hline Variables & & Morphea & MEP & GM & LM & Control \\
\hline \multirow{5}{*}{$\begin{array}{l}\text { Expression in PBMC } \\
\text { (per million copies } \\
\text { of GAPDH) }\end{array}$} & $n$ & 41 & 20 & 14 & 7 & 47 \\
\hline & Median & 2630 & 2923 & 2524 & 2435 & 1906 \\
\hline & Min. & 1134 & 1161 & 1134 & 1524 & 702 \\
\hline & Max. & 10896 & 10896 & 4706 & 3109 & 7540 \\
\hline & $p$ & $0.004^{*}$ & $0.004^{\star}$ & 0.162 & 0.172 & - \\
\hline \multirow{5}{*}{$\begin{array}{l}\text { Plasma concentration } \\
{[\mathrm{pg} / \mathrm{ml}]}\end{array}$} & $n$ & 41 & 20 & 14 & 7 & 47 \\
\hline & Median & 10 & 10 & 10 & 11 & 10 \\
\hline & Min. & 0.0 & 0.0 & 8 & 6 & 4 \\
\hline & Max. & 40 & 25 & 40 & 18 & 104 \\
\hline & $p$ & 0.639 & 0.638 & 0.945 & 0.579 & - \\
\hline \multirow{5}{*}{$\begin{array}{l}\text { Expression in skin } \\
\text { (per million copies } \\
\text { of GAPDH) }\end{array}$} & $n$ & 29 & 13 & 10 & 6 & 13 \\
\hline & Median & 9116 & 12743 & 9976 & 6816 & 19113 \\
\hline & Min. & 0.0 & 2149 & 0.0 & 2200 & 6907 \\
\hline & Max. & 2899083 & 79534 & 2899083 & 39256 & 223284 \\
\hline & $p$ & $0.036^{\star}$ & 0.151 & 0.162 & $0.025^{\star}$ & - \\
\hline
\end{tabular}

PBMC - peripheral blood mononuclear cells, $n$ - number of patients, $p$-value of $p$ related to the control group, other abbreviations - see Table II; *significant difference

Table IV. Expression of IL-23 gene in PBMC, its plasma concentration and cutaneous expression in the study and control groups

\begin{tabular}{|c|c|c|c|c|c|c|}
\hline Variables & & Morphea & MEP & $\mathrm{GM}$ & $L M$ & Control \\
\hline \multirow{5}{*}{$\begin{array}{l}\text { Expression in PBMC } \\
\text { (per million copies } \\
\text { of GAPDH) }\end{array}$} & $n$ & 41 & 20 & 14 & 7 & 47 \\
\hline & Median & 4419 & 4542 & 4680 & 3009 & 808 \\
\hline & Min. & 720 & 1350 & 720 & 1005 & 106 \\
\hline & Max. & 10711 & 10711 & 6843 & 5908 & 8682 \\
\hline & $p$ & $<0.001^{\star}$ & $<0.001^{\star}$ & $<0.001^{\star}$ & $0.007^{*}$ & - \\
\hline \multirow{5}{*}{$\begin{array}{l}\text { Plasma concentration } \\
{[\mathrm{pg} / \mathrm{ml}]}\end{array}$} & $n$ & 41 & 20 & 14 & 7 & 47 \\
\hline & Median & 5 & 6 & 1 & 12 & 6 \\
\hline & Min. & 0.0 & 0.0 & 0.0 & 5 & 0.0 \\
\hline & Max. & 161 & 75 & 137 & 161 & 89 \\
\hline & $p$ & 0.335 & 0.281 & 0.08 & 0.09 & - \\
\hline \multirow{5}{*}{$\begin{array}{l}\text { Expression in skin } \\
\text { (per million copies } \\
\text { of GAPDH) }\end{array}$} & $n$ & 29 & 13 & 10 & 6 & 13 \\
\hline & Median & 292 & 228 & 696 & 305 & 427 \\
\hline & Min. & 9 & 42 & 67 & 9 & 8 \\
\hline & Max. & 97706 & 767 & 97796 & 516 & 927 \\
\hline & $p$ & 0.383 & 0.136 & 0.475 & 0.203 & - \\
\hline
\end{tabular}

Abbreviations - see Tables II and III 
IL-23 was higher: in $\mathrm{LM} p=0.008$ and in $\mathrm{GM} p<0.001$ (Tables III and IV).

No significant differences were found in plasma concentrations of the two proteins in the entire study group or in the subgroups, as compared to the control group (Tables III and IV).

Significantly lower expression of IL-17A was noted in the skin of morphea patients $(p=0.036)$. Analysis of IL-17A expression in the skin in the subgroups demonstrated its lowered expression in the LM subgroup ( $p=0.020)$, but not in MEP or GM, as compared to the control group. No significant differences were noted in expression of IL-23 in skin in the entire study group or in the subgroups, as compared to the control group (Tables III and IV).

A negative correlation was detected between expression of IL-23 in PBMC of MEP patients and LoSSI (rho $=-0.51, p=0.020$ ), between expression of IL-17A in PBMC and LoSSI in the GM subgroup (rho $=-0.65, p=0.010$ ), and in the latter subgroup also between expression of IL-23 in PBMC and LoSSI (rho $=-0.70, p=0.005$ ). No such relationships were found, however, either in the entire study group or in the LM subgroup.

A negative correlation was noted between duration of the disease on one hand and: (1) expression of IL-17A in PBMC (rho $=-0.55, p=0.04$ ) in the entire group of patients; (2) expression of IL-23 in PBMC (rho $=-0.55, p=0.04$ ) in the entire group of patients; (3) expression of IL-23 in the skin ( $r$ o $=-0.74, p=0.01$ ). The latter correlation was seen only in the GM subgroup. No relationships could be detected between plasma concentration of either protein and duration of the disease or between expression of IL-17A in the skin and duration of the disease both in the entire study group and in the subgroups.

Only in the GM subgroup was a negative correlation documented between ANA titre and expression of IL-17A in the skin ( $r h o=-0.70$ at $p=0.020$ ). Moreover, no relationship was seen between ANA titre and expression of studied genes in PBMC or the plasma concentrations of their respective proteins. Similarly, no relationships were found between expression of IL-23 in the skin and ANA titre either in the entire study group or in the subgroups.

\section{Discussion}

In the context of diseases accompanied by fibrosis, IL-17A focuses attention due to its involvement in several pathological phenomena, such as endothelial injury, angiogenesis, autoaggression, or disturbed turnover of intracellular matrix [13-19]. Nevertheless, the results of studies, which so far have been focused exclusively on SSc, are equivocal. In SSc patients both increased expression of IL-17 in PBMC and the absence of such differences,
Table V. ANA evaluated by indirect immunofluorescence

\begin{tabular}{|lcccc|}
\hline $\begin{array}{l}\text { ANA } \\
\text { titre }\end{array}$ & $\begin{array}{c}\text { Morphea } \\
(n=41)\end{array}$ & $\begin{array}{c}\text { MEP } \\
(n=20)\end{array}$ & $\begin{array}{c}\text { GM } \\
(n=14)\end{array}$ & $\begin{array}{c}\text { LM } \\
(n=7)\end{array}$ \\
\hline 0 & 8 & 4 & 3 & 1 \\
\hline $1 / 80$ & 13 & 6 & 6 & 1 \\
\hline $1 / 160$ & 7 & 4 & 2 & 1 \\
\hline $1 / 320$ & 6 & 5 & 0 & 1 \\
\hline $1 / 640$ & 3 & 0 & 2 & 1 \\
\hline $1 / 1280$ & 3 & 0 & 1 & 2 \\
\hline $1 / 2560$ & 1 & 1 & 0 & 0 \\
\hline
\end{tabular}

ANA - anti-nuclear antibodies, other abbreviations - see Table II

as compared to healthy control groups, were observed [10, 25]. Kurasawa et al. and Murata et al. detected elevated serum levels of IL-17, but the results could not be confirmed by Radstake et al. $[10,12,13]$. In this study we have attempted to characterize involvement of IL-17A in pathogenesis of morphea. Higher expression of IL-17A has been demonstrated in PBMC of patients with morphea, accompanied by absence of significant differences in its plasma concentration between the patients and the control group and, moreover, by lowered expression in the affected skin, particularly in the skin sampled from LM patients. What is more, no significant relationships were found between expression of IL-17A in PBMC, its plasma concentration or its expression in the skin on one hand and severity of the disease course in the entire study group, expressed by the LoSSI index. On the other hand, a negative correlation between expression of IL-17A in PBMC and LoSSI was observed in the GM subgroup, the more severe subgroup of the disease. A negative correlation between duration of the disease and expression of IL-17A in PBMC was detected exclusively in the subgroup of GM patients. It is worth stressing that the course of GM used to be longer than that of MEP, which might have influenced the results obtained in the entire study group. However, such considerations should be drawn with caution because of the small size of the study subgroups. Literature on the subject contains results pointing to a correlation between serum concentrations of IL-17 and early stages of SSc [10, 12]. On the other hand, our results have failed to demonstrate potential relationships between IL-17A and total ANA in the entire study group, although a negative correlation was found between expression of IL-17A in the skin of GM patients and ANA titre. A similar analysis was conducted by Kurasawa et al. in a group of SSc patients and they failed to note any relationship between IL-17 and ANA titre [10]. Summing up, it seems that IL-17A does not seem to play a role as a tissue damaging factor in the course 
of morphea. Moreover, it should be accentuated that higher expression of IL-17A in PBMC of patients with GM, the more severe form of morphea, was correlated with a more benign course of the disease and in the same group its higher expression in the skin showed a correlation with lower ANA titres. In this context, observations made on a mouse model of colitis are interesting: IL-17A was supposed to exert a simply protective action, while the process was aggravated by IL-17F [27]. However, the latter protein has not been analysed in this study.

Interleukin-23 represents the main protein which stimulates and augments synthesis of IL-17 [20, 21]. Its significance has been well documented in many inflammatory and autoimmune diseases and this resulted in development of biological drugs counteracting the protein. The drugs are at present widely and successfully used, e.g. in psoriasis [28]. It should be noted that its pathogenic effect does not always necessarily reflect IL-17-mediated reactions and, e.g., psoriatic acanthosis depends rather on IL-23-induced tumour necrosis factor (TNF)- $\alpha$ [28]. In SSc elevated plasma levels of IL-23 were documented [13, 29] and it was suggested that they indicated early stages of the disease [29]. However, upon examining morphea patients we failed to demonstrate elevated plasma concentrations of the protein or its increased expression in the skin, although we noted its increased expression in PBMC. Interestingly, we also observed a negative correlation between IL-23 expression in PBMC and LOSSI, but exclusively in the MEP and GM subgroups. In parallel, higher expression of IL-23 in PBMC was noted at early stages of GM, but the size of this subgroup was small. No relationship was found between ANA and IL-23 in morphea. The above observations may suggest that IL-23 may play a certain role in pathogenesis of morphea, although mainly in its preliminary phases.

In conclusion, the presented results document increased expression of IL-17A and IL-23 in PBMC of morphea patients and lowered expression of IL-17A in skin of the patients. On the basis of the demonstrated correlations we suggest that in the studied disease IL-17A does not represent a factor which promotes tissue injury. Nevertheless, the limitations of the study need to be stressed, concerning, first of all, the small groups of unequal size. No studies are available which would unequivocally justify the choice of GAPDH as the reference gene in fibrotic skin and in this scope the studies should be repeated using also other reference genes. Finally, the study included only IL-17A, and it would deserve extension to IL-17F, the significance of which was demonstrated in a mouse model of colitis [27]. Also the remaining cytokines of the IL-17 family, IL-17B, IL-17C and IL-17D, may demonstrate a slightly altered activity, in particu- lar because their homology to IL-17 A is smaller than that between IL-17A and F [14]. Evaluation of expression involving receptors of the studied cytokines would also be of interest. In SSc increased expression of the IL-17A receptor was observed even if in the same group of patients no increased expression of the cytokine could be detected in PBMC [25]. Therefore, it seems that our results provide just an introduction to studies on the role of the relatively recently discovered cytokine family in pathogenesis of morphea.

\section{Acknowledgments}

The research reported here and the preparation of this manuscript were funded by Ministry of Science and Higher Education of Poland (grant N N402 371338)

\section{References}

1. Peterson LS, Nelson AM, Su WPD. Classification of morphea (localized scleroderma). Mayo Clin Proc 1995; 70: 1068-76.

2. Takehara K, Sato S. Localized scleroderma is an autoimmune disorder. Rheumatology 2005; 44: 274-9.

3. Kreuter A, Krieg T, Worm M, et al. Diagnosis and therapy of localized scleroderma. J Deutsch Dermatol Ges 2009; 7 suppl. 6: S1-14.

4. Reich A, Heisig M, Baran E. Werner syndrome - a premature aging syndrome that can mimic scleroderma. Postep Derm Alergol 2010; 27: 490-4.

5. Nedoszytko B. Genetically determined syndromes associated with premature aging. Postep Derm Alergol 2010; 27: 282-90.

6. Akimoto S, Ishikawa O, Yokoyama Y., Amano H, Miyachi Y. Generalized morphea with vascular involvement. A case report and disaccharide analysis of the skin glycosaminoglycans. Acta Derm Venereol 1996; 76: 141-3.

7. Sgonc R, Gruschwitz MS, Dietrich H, Recheis H, Gershwin ME, Wick G. Endothelial cell apoptosis is a primary pathogenic event underlying skin lesions in avian and human scleroderma. J Clin Invest 1996; 98: 785-92.

8. Xie Y, Zhang X, Wakasugi S, Makino T, Inoue Y, Ihn H. Immunohistochemical characterization of the cellular infiltrate in localized scleroderma. Int J Dermatol 2008; 47: 438-42.

9. Dziankowska-Bartkowiak B, Gerlicz-Kowalczuk Z, Waszczykowska E. Angiogenin and SDF-1alpha serum concentration in patients with systemie sclerosis In relation to clinical status. Arch Med Sci 2011; 7: 92-96.

10. Kurasawa K, Hirose K, Sano H, et al. Increased interleukin-17 production in patients with systemic sclerosis. Arthritis Rheumatism 2000; 43: 2455-63.

11. Alexandrakis MG, Pappa CA, Miyakis S, et al. Serum interleukin-17 and its relationship to angiogenic factors in multiple myeloma. Eur J Int Med 2006; 17: 412-6.

12. Murata M, Fujimoto M, Matsushita T, et al. Clinical association of serum interleukin-17 levels in systemic sclerosis: is systemic sclerosis a Th17 disease? J Dermatol Sci 2008; 50: 240-2.

13. Radstake TRDJ, van Bon L, Broen J, et al. The pronounced Th17 profile in systemic sclerosis (SSc) together with intracellular expression of TGFbeta and INFgamma distinguishes SSc Phenotypes. PLoS ONE 2009; 4: e5903. 
14. Pappu R, Ramirez-Carrozzi V, Ota N, Ouyang W, Hu Y. The IL-17 family cytokines in immunity and disease. J Clin Immunol 2010; 30: 185-95.

15. Hemdan NYA, Birkenmeier G, Wichmann G, et al. Interleukin-17-producing $T$ helper in autoimmunity. Autoimmunity Rev 2010; 9: 785-92.

16. Onishi RM, Gaffen SL. Interleukin-17 and its target genes: mechanisms of interleukin-17 function in disease. Immunology 2010; 129: 311-21.

17. Numasaki M, Watanabe M, Suzuki T, et al. IL-17 enhances the net angiogenic activity and in vivo growth of human non-small cel lung cancer in SCID mice through promoting CXCR-2-dependent angiogenesis. J Immunol 2005; 175: 6177-89.

18. Takahashi H, Numasaki M, Lotze MT, Sasaki H. Interleukin-17 enhances bFGF-, HGF- and VEGF-induced growth of vascular endothelial cells. Immunology Letters 2005; 98: 189-93.

19. Zhu F, Wang Q, Guo C, et al. IL-17 induces apoptosis of vascular endothelial cells - a potential mechanism for human acute coronary syndrome. Clin Immunol 2011; 141: 152-60.

20. Aggarwal S, Ghilardi N, Xie MH, de Sauvage FJ, Gurney AL. Interleukin-23 promotes a distinct CD4 T cell activation state characterized by the production of intrleukin-17. J Biol Chem 2003; 278: 1910-4.

21. Costa VS, Mattana TCC, da Silva MER. Unregulated IL-23/IL-17 immune response in autoimmune diseases. Diabetes Res Clin Pract 2010; 88: 222-6.

22. Arkachaisri T, Pino S. Localized scleroderma severity index and global assessment: a pilot study of outcome instruments. J Rheumatol 2008; 35: 650-7.

23. Chomczyński P, Sacchi N. Single step method of RNA isolation by acid guanidinium thiocyanate-phenolchloroform extraction. Anal Biochem 1987; 162: 156-9.

24. Pattyn F, Speleman F, De Paepe A, Vandesompele J. RTPrimerDB: the real-time PCR primer and probe database. Nucleic Acids Research 2003; 31: 122-3.

25. Namyst J, Osmola A, Prokop J. Expression of human endogenous retrovirus sequences in patients with generalised scleroderma and various clinical forms of psoriasis [Polish]. Postep Derm Alergol 2005; 22: 99-104.

26. Bonnet-Duquennoy M, Abaibou H, Tailhardt M, et al. Study of housekeeping gene expression in human keratinocytes using OLISATM, a long-oligonucleotide microarray and qRT-PCR. Eur J Dermatol 2006; 16: 136-40.

27. Ogawa A, Andoh A, Araki Y, Bamba T, Fujiyama Y. Neutralization of interleukin-17 aggravates dextran sulphate sodium-induced colitis in mice. Clin Immunol 2004; 110: 55-62.

28. vanBeelen AJ, Teunissen MBM, Kapsenberg ML, de Jong EC. Interleukin-17 in inflammatory skin disorders. Curr Opin Allergy Clin Immunol 2007; 7: 374-81.

29. Komura K, Fujimoto M, Hasegawa M, et al. Increased serum interleukin 23 in patients with systemic sclerosis. J Rheumatol 2008; 35: 120-5. 